\title{
EDUKASI HIGIENE SANITASI INDUSTRI PADA PEKERJA INDUSTRI RUMAH TANGGA KERUPUK DI DESA KANDANGAN KREMBUNG SIDOARJO
}

\section{INDUSTRIAL SANITATION HYGIENE EDUCATION IN THE HOME INDUSTRY OF CRACKERS IN KANDANGAN VILLAGE KREMBUNG SIDOARJO}

\author{
M. Nilzam Aly ${ }^{1}$, Andhini Aurelia Putri*², Indah Budi Lestari ${ }^{2}$, Bunga Natanael \\ Mega $\mathbf{P}^{2}$, Maulidiyatun Nafiisah ${ }^{2}$, Izza Mahendra ${ }^{2}$, Neni Haqnanda Dimi ${ }^{2}$, \\ Rosaline Dinda Arista ${ }^{2}$, Deviyanty Ristia Ayu $\mathbf{P}^{3}$, Berliana Purnaning Samsara ${ }^{3}$ \\ ${ }^{1}$ Fakultas Vokasi, Universitas Airlangga, ${ }^{2}$ Fakultas Kesehatan Masyarakat, Universitas \\ Airlangga, ${ }^{3}$ Fakultas Ilmu Budaya, Universitas Airlangga \\ email: andhini.aurelia.putri-2017@fkm.unair.ac.id
}

\begin{abstract}
Industrial sanitation hygiene education program for crackers home industry workers in Kandangan village, Krembung sub-district, Sidoarjo district was chosen as the Community Work Study Program (KKN-BBM) because: (1) In 2020, in Kandangan Village there were around 52 crackers home industries which has entered the second generation so it must be maintained; (2) The application of sanitation hygiene in the crackers home industry in Kandangan Village is generally still far from the established standards; (3) Poor hygiene practices can cause things that are detrimental to consumers, such as food poisoning or foodborne diseases. The author involved 10 crackers home industry workers as fostered partners during $\mathrm{KKN}$ activities taking place in industrial sanitation hygiene education on crackers home industry workers. The program is carried out with the delivery of material regarding sanitary hygiene requirements to control risk factors for food contamination, both those originating of food ingredients, people, places and equipment. To evaluate this activity, pre-test is given before delivering the material and post-test after delivering the material. From the results of the activities, this program has been proven to increase worker's knowledge regarding sanitation hygiene requirements that must be carried out by crackers home industry managers and workers. Even though industrial sanitation hygiene education activities are more material in nature, it is expected to be a trigger to increase worker's awareness about the importance of implementing industrial sanitation hygiene and making it a daily habit. This is because one important factor that supports the creation of food security is the condition of good food processing sanitation and hygiene.
\end{abstract}

Keywords: Education, Industrial, Sanitation Hygiene, Home Industry

\section{abstrak}

Program edukasi higiene sanitasi industri pada pekerja industri rumah tangga kerupuk di Desa Kandangan, Kecamatan Krembung, Kabupaten Sidoarjo dipilih sebagai program Kuliah Kerja Nyata Belajar Bersama Masyarakat (KKN-BBM) karena: (1) Pada tahun 2020, di Desa Kandangan terdapat sekitar 52 industri kerupuk yang sudah masuk pada generasi kedua sehingga harus dipertahankan; (2) Penerapan higiene sanitasi pada industri rumah tangga kerupuk di Desa Kandangan umumnya masih jauh dari standar yang sudah ditetapkan; (3) Praktek sanitasi higiene yang kurang baik dapat menimbulkan hal-hal yang merugikan konsumen, seperti keracunan makanan maupun penyakit yang ditularkan melalui makanan. Penulis melibatkan 10 pekerja industri rumah tangga kerupuk sebagai mitra binaan selama kegiatan KKN berlangsung dalam edukasi higiene sanitasi industri pada pekerja industri rumah 
tangga kerupuk.Program ini dilakukan dengan penyampaian materi mengenai persyaratan higiene sanitasi untuk mengendalikan faktor risiko terjadinya kontaminasi terhadap makanan, baik yang berasal dari bahan makanan, orang, tempat dan peralatan.Untuk mengevaluasi kegiatan ini dilakukan pemberian pre-test sebelum penyampaian materi dan post-testsetelah penyampaian materi.Dari hasil kegiatan, program ini terbukti meningkatkan pengetahuan pekerja mengenai persyaratan higiene sanitasi yang harus dilakukan oleh pengelola industri rumah tangga dan para pekerja.Walaupun kegiatan edukasi higiene sanitasi industri lebih bersifat pembekalan materi tapi diharapkan dapat menjadi suatu pemicu untuk meningkatkan kesadaran para pekerja tentang pentingnya menerapkan higiene sanitasi industri serta menjadikannya kebiasaan sehari-hari.Hal ini dikarenakan salah satu faktor penting yang mendukung terciptanya keamanan pangan adalah kondisi sanitasi dan higiene pengolahan pangan yang baik.

Kata Kunci: Edukasi, Industri, Higiene Sanitasi, Industri rumah tangga

\section{PENDAHULUAN}

Kabupaten Sidoarjo merupakan salah satu kabupaten di Provinsi Jawa Timur yang memiliki 18 Kecamatan dan dibagi menjadi 322 desa dan 31 kelurahan.Setiap desa memiliki potensi dan sumber daya tersendiri untuk meningkatkan ekonomi di desanya.Salah satu potensi tersebut yaitu industri rumah tanggakerupuk yang ada di Desa Kandangan, Kecamatan Krembung Kabupaten Sidoarjo.

Berdasarkan sidoarjoterkini.com pada tahun 2020, di Desa Kandangan terdapat sekitar 52 industri kerupuk yang sudah masuk pada generasi kedua.Sehingga, hal tersebut harus tetap dipertahankan.Kondisi tersebut tentunya menunjukkan betapa besarnya potensi laju ekonomi yang dimiliki Desa kandangan melalui industri rumah tangga kerupuknya.Menurut (Triharjono dkk, 2013) perusahaan yang bergerak dalam bidang pangan seharusnya senantiasa mengarahkan kegiatan usahanya untuk menghasilkan produk yang memenuhi standar keamanan pangan serta memberikan kepuasan bagi konsumen.Hal ini disebabkan oleh semakin meningkatnya minat konsumen terhadap produk yang bersih, sehat, dan aman.

Pada penelitian terdahulu (Suwandewi, Rusminingsih, dan Purna. 2019) yang dilakukan di industri rumah tangga olahan makanan, sebagian besar yang menjadi masalah yaitu kondisi bangunan dan fasilitas serta personal higiene dari karyawan di suatu industri rumah tangga.Hal serupa juga disebutkan pada penelitian (Floridiana. 2018) yang mengatakan bahwa yang menjadi masalah dalam higienesanitasi industri yaitu higienepenjamah makanan yang tidak mematuhi peraturan.Seluruh pekerja tidak menggunakan pakaian khusus dan sebagian besar pekerja laki-laki merokok di lingkungan industri rumah tangga.Selain itu, hampir semua pekerja tidak menggunakan Alat Pelindung Diri (APD) saat bekerja.Kondisi serupajuga terjadi di industri rumah tangga kerupuk di Desa Kandangan.

Penerapan higiene sanitasi pada industri rumah tangga kerupuk di Desa Kandangan umumnya masih jauh dari standar yang sudah ditetapkan.Padahal seperti yang kita ketahui bahwa salah satu faktor penting yang mendukung terciptanya keamanan pangan adalah kondisi sanitasi dan higiene pengolahan pangan.Praktek sanitasi higieneyang kurang baik dapat menimbulkan hal-hal yang merugikan konsumen, seperti keracunan makanan maupun penyakit yang ditularkan melalui makanan (Domili, 2017).Namun, 
berdasarkan hasil observasi potensi laju ekonomi akibat industri rumah tangga kerupuk di Desa Kandangan, tidak diikuti dengan kualitas higieneindustri sanitasi makanan para pekerjanya. Kondisi inilah yang menjadi pertimbangan kami untuk melakukan kegiatan penyuluhan terkait pentingnya higiene sanitasi makanan bagi para pekerja industri rumah tangga kerupuk di Desa kandangan.

Melalui kegiatan tersebut diharapkan dapat meningkatkan pengetahuan pekerja industri rumah tangga kerupuk terkait higienesanitasi makanan industri rumah tangga kerupuk yang ada di Desa Kandangan, Kecamatan Krembung, Kabupaten Sidoarjo.

\section{METODE PENGABDIAN MASYARAKAT}

Program higiene sanitasi dilaksanakan pada 16 Juli 2020 dan diikuti oleh 10 peserta dari salah satu industri rumah tanggakerupuk yang berada di desa Kandangan kecamatan Krembung kabupaten Sidoarjo.Program ini hanya dilaksanakan di salah satu industri rumah tanggauntuk menghindari kerumunan dan mengurangi dampak penyebaran coronavirus sesuai dengan anjuran gugus tugas percepatan COVID-19 di Indonesia.

\section{Analisis Komunitas}

\section{Pengumpulan Data}

Pengumpulan data terkait daerah sasaran dilakukan oleh tim seperti mencari informasi tentang industri rumah tangga kerupuk yang menjadi salah satu penggerak perekonomian di daerah tersebut.

\section{Survei Lokasi}

Studi lingkungan dilakukan melalui survei lokasi dimana desa Kandangan kecamatan Krembung kabupaten Sidoarjo menjadi daerah sasaran. Hal ini bertujuan untuk mengetahui kondisi industri rumah tanggatermasuk pekerjanya agar program berjalan dengan lancar dan sesuai dengan karakter masyarakat tersebut.

\section{Persiapan Materi dan Media \\ Penyusunan Materi}

Penyusunan materi dilakukan untuk membuat materi yang akan disampaikan kepada masyarakat sasaran menjadi menarik sehingga masyarakat tersebut menjadi antusias mengikuti program higienesanitasi. Dalam proses penyusunannya, materi yang akan disampaikan harus memenuhi indikator keberhasilan seperti affective, cognitive, dan psychomotor.

\section{Penyusunan Media}

Media yang digunakan dalam kegiatan tersebut adalah poster.Poster berisi gambar dan penjelasan singkat mengenai higiene sanitasi.Poster dianggap cukup untuk membuat masyarakat tertarik, lebih lanjut poster juga bisa ditempel agar masyarakat selalu mengingat pentingnya kegiatan higiene sanitasi.

\section{Pelaksanaan Kegiatan \\ Perkenalan dan Sosialisasi}

Kegiatan higiene sanitasi dilaksanakan di salah satu industri rumah tanggapada tanggal 16 Juli 2020.Sosialisasi hanya melibatkan 10 pekerja sesuai untuk menerapkan physical distancing. Sosialisasi bertujuan untuk mengenalkan program, tujuan pelaksanaan, dan memberikan edukasi mengenai pentingnya program tersebut.

\section{Pelaksanaan Program}

\section{Pre-Test}


Sesuai dengan namanya, pre-test dilaksanakan sebelum pekerja mendapatkan materi mengenai higiene sanitasi.Tujuan kegiatan ini adalah untuk mengetahui pemahaman mereka tentang higiene sanitasi.

\section{Pembekalan Materi}

Penyampaian materi dilakukan pada hari yang sama dengan sosialisasi, dimana melibatkan 10 pekerja dari salah satu industri rumah tangga. Materi yang disampaikan meliputi pengertian, tujuan, dan hal-hal yang harus diperhatikan untuk memenuhi standar higiene sanitasi dalam industri rumah tanggakerupuk.

\section{Evaluasi}

Post-Test

Post-test dilakukan setelah para pekerja mendapatkan pembekalan materi yang bertujuan untuk mengetahui tingkat pengetahuan mengenai higiene sanitasi.

\section{Monitoring}

Pemantauan dilakukan untuk mengetahui perkembangan kemampuan para pekerja industri rumah tanggakerupuk.

\section{Controlling}

Controllingdilaksanakan secara berkala untuk mengetahui perkembangan pencapaian program higienesanitasi.

\section{HASIL DAN PEMBAHASAN}

Kegiatan pengabdian masyarakat yang dilakukan yakni memberikan edukasi higiene sanitasi industri pada pekerja industri rumah tangga Kerupuk di Desa Kandangan, Kecamatan Krembung, Kabupaten Sidoarjo dengan tujuan untuk meningkatkan pengetahuan pekerja terkait higiene sanitasi pengolahan makanan.Kegiatan ini dilakukan pada tanggal 16 Juli 2020 dan diikuti oleh 10 pekerja. Dimulai dengan pemberian pre-test sebelum edukasi dilakukan diberikan sebanyak 5 pertanyaan, kemudian diberikan penyuluhan dan setelah itu diberikan post-test dengan pertanyaan yang sama. Indikator yang digunakan sebagai tolak ukur keberhasilan edukasi yang dilakukan adalah meningkatnya nilai pada post-test setelah pemberian edukasi diberikan.Para pekerja rata-rata yakni ibu rumah tangga yang berusia cukup lanjut.

Pelaksanaan edukasi mengenai higiene sanitasi industri pada kegiatan pengabdian masyarakat ini menggunakan metode edukasi atau penyuluhan dengan poster yang berisi tentang persyaratan higienesanitasi industri.Selain menggunakan poster, edukasi dilakukan melalui video.Hal ini dilakukan untuk menambah pengetahuan yang dimiliki para pekerja sehingga para pekerja diharapkan dapat membuat produk makanan yang bermutu dan aman untuk dikonsumsi dan juga agar pekerja terhindar dari bahaya yang dapat terjadi di tempat kerja.Tenaga kerja yang sehat dan produktif merupakan aset penting dalam peningkatan keberhasilan suatu perusahaan atau tempat kerja, sehingga sebuah perusahaan atau industri harus mampu memberikan fasilitas terbaik seperti kesejahteraan ataupun kenyamanan sehingga mereka dapat bekerja secara maksimal dan mendukung tingkat produktivitas.

Program edukasi higiene sanitasi industri pada pekerja industri rumah tangga Kerupuk Trijaya, Desa Kandangan, Kecamatan Krembung, Kabupaten Sidoarjo berhasil meningkatkan pengetahuan pekerja. Hal ini dapat dilihat pada tabel hasil pre-test dan 
post-test, hasil tersebut menunjukkan bahwa terjadi peningkatan pengetahuan pada pekerja yang semula memiliki nilai rata-rata 20 meningkat bervariasi menjadi 30,40 dan 50. Sebelumnya para responden atau pekerja belum sepenuhnya mengetahui apa itu higiene sanitasi industri, namun setelah diberikan edukasi terjadi peningkatan pengetahuan.

\section{Tabel dan Gambar}

Tabel 1. Hasil Pre-test dan Post-test Pekerja Industri rumah tanggaKerupuk X

\begin{tabular}{clcc}
\hline \multirow{2}{*}{ No. } & \multirow{2}{*}{ Nama Pekerja } & \multicolumn{2}{c}{ Nilai } \\
\cline { 3 - 4 } & & Pre-test & Post-test \\
\hline 1. & Responden 1 & 20 & 30 \\
2. & Responden 2 & 20 & 40 \\
3. & Responden 3 & 20 & 50 \\
4. & Responden 4 & 20 & 50 \\
5. & Responden 5 & 20 & 30 \\
6. & Responden 6 & 20 & 40 \\
7. & Responden 7 & 20 & 40 \\
8. & Responden 8 & 0 & 40 \\
9. & Responden 9 & 20 & 40 \\
10. & Responden 10 & 20 & 40 \\
\hline
\end{tabular}

Terlihat adanya peningkatan pengetahuan tentang higiene sanitasi industri yang disebabkan karena adanya edukasi dan penyuluhan.Notoatmodjo (2012) berargumen bahwa edukasi merupakan pengalaman belajar yang dapat mempengaruhi sikap, dan perilaku seseorang.Edukasi sebagai salah satu metode promosi kesehatan penting bagi perubahan sikap para pekerja dalam menerapkan higiene dan sanitasi yang lebih baik lagi.Perubahan pengetahuan tentang pentingnya higiene dan sanitasi industri dapat mencegah terjadinya bahaya di tempat kerja.Walaupun kegiatan edukasi higiene sanitasi industri lebih bersifat pembekalan materi tapi diharapkan dapat menjadi suatu pemicu untuk meningkatkan kesadaran para pekerja tentang pentingnya menerapkan higiene sanitasi industri serta menjadikannya kebiasaan sehari-hari.

Berdasarkan Undang - Undang Republik Indonesia Nomor 18 Tahun 2012 Tentang Pangan, higiene sanitasi dilakukan agar pangan dapat dikonsumsi dengan aman. dalam pengendalian risiko bahaya pada pangan, setiap orang yang terlibat dalam rantai pangan wajib mengendalikan risiko bahayanya, baik yang berasal dari bahan baku makanan, peralatan yang digunakan, sarana, proses produksi maupun perseorangan sehingga keamanan terjamin. selain itu, perseorangan yang menyelenggarakan atau terlibat dalam proses produksi, penyimpanan, pengangkutan, dan/atau peredaran diwajibkan untuk memenuhi persyaratan sanitasi serta menjamin keamanan pangan untuk keselamatan manusia.

Berdasarkan Peraturan Kepala BPOM Republik Indonesia Nomor HK.03.1.23.04.12.2206 Tahun 2012 Tentang CPPB Untuk Industri Rumah Tangga, kesehatan dan higiene karyawan yang baik dapat menjamin bahwa karyawan yang kontak langsung maupun tidak langsung dengan pangan tidak menjadi sumber pencemaran. Edukasi yang dilakukan menjadi sarana untuk menambah pengetahuan bagi karyawan yang bekerja dengan bertambahnya pengetahuan diharapkan mampu menjadi faktor pendorong untuk perubahan perilaku karyawan agar selalu menjaga 
kebersihan selama kontak langsung maupun tidak langsung dengan makanan. Kebiasaan menjaga kebersihan bagi karyawan akan berpengaruh pada keamanan pangan. Kegiatan edukasi terhadap karyawan seharusnya dilakukan secara berkala serta dipantau ketepatan dan keefektifannya dan jika perlu dilakukan pencatatan.

\section{PENUTUP}

\section{Simpulan}

Berdasarkan hasil analisa dan pembahasan mengenai edukasi higiene sanitasi industri di salah satu industri rumah tangga kerupuk Desa Kandangan, Krembung, didapatkan kesimpulan sebagai berikut:

1. Karakteristik pekerja yang mengikuti program edukasi higiene sanitasi industri adalah ibu rumah tangga berusia lanjut.

2. Program edukasi higiene sanitasi industri menggunakan media poster dan video untuk memudahkan penyampaian materi yang disertai dengan pemberian pretest dan post-test kepada para pekerja.

3. Terjadi peningkatan pengetahuan mengenai edukasi higiene sanitasi industri pada pekerja di salah satu industri rumah tangga kerupuk Desa Kandangan, Krembung. Hal tersebut dapat dilihat dari adanya peningkatan nilai pekerja dari pre-test ke post-test.

4. Program edukasi higienesanitasi industri dinyatakan berhasil mencapai tujuan yang diinginkan. Terjadinya peningkatan nilai dari pre-test ke post-test pada pekerja merupakan tolak ukur keberhasilan program ini.

\section{Saran}

Saran yang dapat penulis berikan untuk industri rumah tangga kerupuk Desa Kandangan, Krembung, adalah sebagai berikut:

1. Penerapan mengenai higienesanitasi industri penting untuk dilakukan oleh pemilik maupun pekerja agar industri rumah tangga krupuk dapat menghasilkan produk yang bermutu dan aman dikonsumsi, serta agar pekerja terhindar dari bahaya atau kecelakaan saat bekerja.

2. Perlu dilakukan pengawasan dan evaluasi secara rutin terhadap sistem kerja industri rumah tangga kerupuk Desa Kandangan, Krembung untuk menjaga mutu produk serta menjaga produktivitas pekerja.

\section{UCAPAN TERIMA KASIH}

Penulis mengucapkan terima kasih kepada LPPM Universitas Airlangga yang telah memberi dukungan finansial terhadap pengabdian ini.

\section{DAFTAR PUSTAKA}

Anonymous (2020) BHS Kunjungi pelaku Usaha Kerupuk di Krembung, Siapkan Swasembada Tepung di Sidoarjo, Sidoarjoterkini.com. Available at: https://sidoarjoterkini.com/2020/04/07/bhs-kunjungi-pelaku-usaha-kerupuk-di- 
krembung-siapkan-swasembada-tepung-di-sidoarjo/ (Accessed: 27 July 2020).

Badan Pengawas Obat dan Makanan Republik Indonesia (2012) Peraturan Kepala Badan Pengawas Obat dan Makanan Republik Indonesia Nomor HK.03.1.23.04.12.2206 Tahun 2012 tentang Cara Produksi Pangan yang Baik untuk Industri Rumah Tangga. Jakarta.

Domili, R. S. (2017) 'Sanitasi dan Hygiene pada Proses Pembuatan Rambak Ikan Buntal Pisang (Tetraodon lunaris) di UKM Jaya Utama Kecamatan Mayangan Kota Probolinggo Jawa Timur', Jurnal Aquabis, 7(2), pp. 1-5.

Floridiana, Z. (2019) 'Analisis Higiene Penjamah Makanan dan Sanitasi Lingkungan pada Industri Rumah Tangga Tahu Jombang 2018', Jurnal Kesehatan Lingkungan, 11(1), pp. 75-82. doi: 10.20473/jkl.v11i1.2019.75-82.

Menteri Kesehatan Republik Indonesia (2011) Peraturan Menteri Kesehatan Republik Indonesia Nomor 1096/Menkes/Per/VI/2011. Jakarta.

Notoatmodjo, S. (2012) Promosi Kesehatan Teori dan Aplikasi. Revisi. Jakarta: Rineka Cipta.

Presiden Republik Indonesia (2012) Undang-Undang Republik Indonesia Nomor 18 Tahun 2012 tentang Pangan. Jakarta.

Suwandewi, N. L. P. A., Rusminingsih, N. K. and Purna, I. N. (2019) 'Gambaran Personal Higiene dan Keadaan Sanitasi Industri Tempe UD Andika Pangaripuan di Desa Tagtag Kaja Kecamatan Denpasar Utara Tahun 2019', Jurnal Kesehatan Lingkungan, 9(2), pp. 109-114.

Triharjono, A., Probowati, B. D. and Fakhry, M. (2013) 'Evaluasi Sanitation Standard Operating Procedures Kerupuk Amplang di UD Sarina Kecamatan Kalianget Kabupaten Sumenep', Jurnal Agrointek, 7(2), pp. 76-83. doi: 10.21107/agrointek.v7i2.2053.g1685.

Wahyu, A. et al. (2019) 'Metode Edukasi \& Pendampingan terhadap Peningkatan Kesadaran terkait Penggunaan APT Pengrajin Pandai Besi', Jurnal Kesehatan Masyarakat Maritim, 2(2), pp. 302-313. 